\title{
AIDS vaccine research becomes 'big science'
}

W ith no vaccine to show for more than 20 years of work, the HIVvaccine community is being forced to radically change the way it works. Funding organizations are insisting on a 'big science' approach involving huge data-sharing collaborations. But AIDS researchers are divided over whether such a strategy will really speed progress towards a vaccine.

When the Bill \& Melinda Gates Foundation announced a US $\$ 300$-million call for proposals in HIV vaccine research last year, it marked a key change for researchers used to chasing investigator-driven grants. Individual groups need not apply, said the foundation. Instead, it demanded that research groups organize themselves into bigger consortia, then jointly submit large, multimillion-dollar proposals with clear milestones and goals. The consortia had to agree to share data with each other, and to ensure that any patents won would allow vaccines to be made available to developing countries at low cost.

Researchers duly did as they were asked, and last month the Gates Foundation announced the winners of 16 grants, totalling $\$ 287$ million over five years. They will establish an international network of 11 vaccine-discovery consortia, plus 5 support and data-analysis facilities - bringing together 165 investigators from 19 countries in a single effort (see 'Some of the winners...').

The move comes a year after the US National Institutes of Health put some $\$ 315$ million over 7 years into a similar group of consortia to create the Center for HIV-AIDS Vaccine Immunology (CHAVI).

The idea of large consortia working on AIDS vaccine research was put forward in 2003 by a group of research funders. It was outlined earlier this year by the Global HIV Vaccine Enterprise, a virtual consortium aimed at accelerating HIV vaccine development that

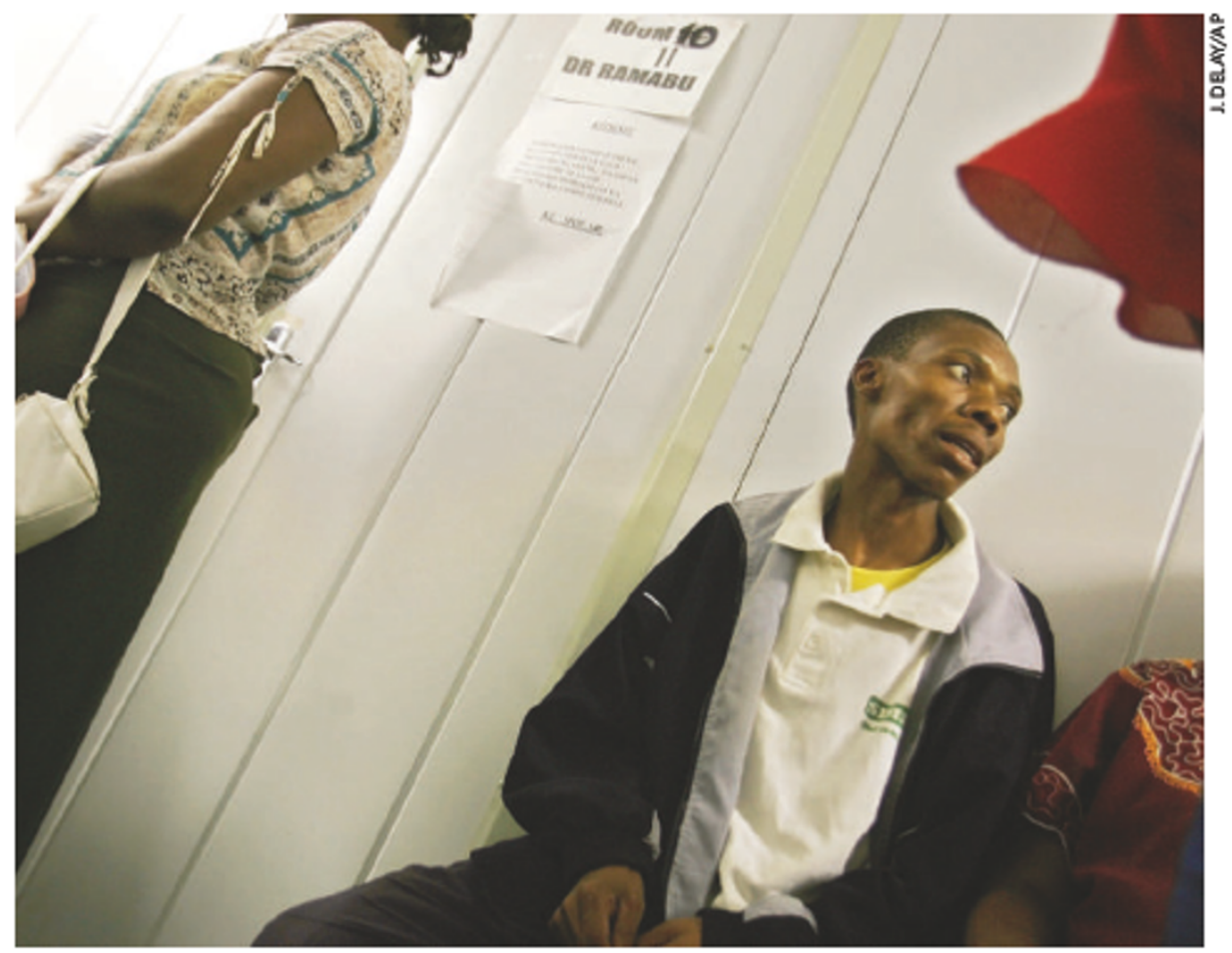

A clutch of consortia will receive US\$287 million in an attempt to alleviate the plight of AIDS sufferers.

was endorsed by the G8 summit in July.

Instead of relying on researchers to form collaborations spontaneously, those with the money are now forcing it to happen, says Michel Kazatchkine, France's ambassador for AIDS and co-chair of the Enterprise coordination committee. Kazatchkine explains that instead of gathering and publishing their own data, researchers will be obliged to work with large, shared data sets, use standardized assays and methods, and farm out routine analyses to a series of centralized laboratories.

Much of this isn't controversial Most AIDS scientists agree that standardized methods are sorely needed, and there is broad support for the $\$ 100$ million that the Gates Foundation is providing for five central facilities to help structure and coordinate the field. At present, groups use different cohorts, assays and surrogate markers. This makes it all but impossible to compare results to find the most promising vaccine candidates for clinical trials. Individual researchers have little incentive to improve matters, as developing standards involves mundane work that does not yield prestigious publications.

More contentious are the 11 research grants to establish vaccine-discovery consortia these are likely to be the talk of the corridors at

\section{Some of the winners...}

HIV poses a formidable challenge for vaccine developers: it mutates rapidly, attacks immune cells that might destroy it, and has an arsenal of tactics to avoid the body's defences, such as molecular shields that protect its surface from attack by antibodies.

AIDS researchers now believe that an effective vaccine will be two-pronged: as well as generating antibodies, it will need to stimulate immune cells.

Of the 11 consortia selected, five will seek ways of generating effective antibodies when the immune system is exposed to HIV.Of these, a consortiumled by Robin Weiss of University College London, who has won a $\$ 25.3$-million grant, willscreen antibodies from humans and animals that seem naturally active against HIV, and then work backwards to see which regions they target and design new vaccine candidates. And a $\$ 19.4$ million grant to a consortium led by Leo Stamatatos at Seattle Biomedical Research Institute willuse computers to design molecules that might trigger antibodies against the virus.

The other six consortia will focus on stimulating a cellular response.
For example, Timothy Zamb of the International AIDS Vaccine Initiative has won $\$ 23.7$ million to try to modify other viruses to act as vectors for the vaccine. And a $\$ 15.3$-million project led by Giuseppe Pantaleo at the Centre Hospitalier Universitaire Vaudois in Laus anne, Switzerland, hopes to improve the ability of poxvirus, a known vaccine vector, to trigger a response to HIV. 


\section{A controversial choice?}

The list of winners of the Gates Foundation grants has come under fire. Some researchers, including some winners, say in private that they are puzzled why certain projects were funded while others seen as more worthy were not.

This reflects the subjective nature of any review, other researchers say. But the secrecy of the process has fuelled speculation about bias. The review panel was anonymous, and researchers didn't receive the referee reports typicallygiven during grant applications.

"The names of the external reviewers were kept confidential to protect them from inappropriate pressures," says José Esparza, senior adviser on HIV vaccines at the Gates Foundation. $\mathrm{He}$ adds that scores and recommendations were not passed toapplicants as it was a one-off competition with no possibility of resubmission, and that potential conflicts of interest were disclosed to panellists andfoundation staff.
Each proposal was reviewed by 11 external experts, says Esparza. The foundation approved the ten highest-scoring projects, then selected four others from a combination of their scores and more subjective criteria, such as "maintaining a balance of projects; supporting novelideas; and ensuring they weren't duplicating projectsalready supported by otherfunders". Two final grants were awarded to central facilities that would support the other projects. D.B.

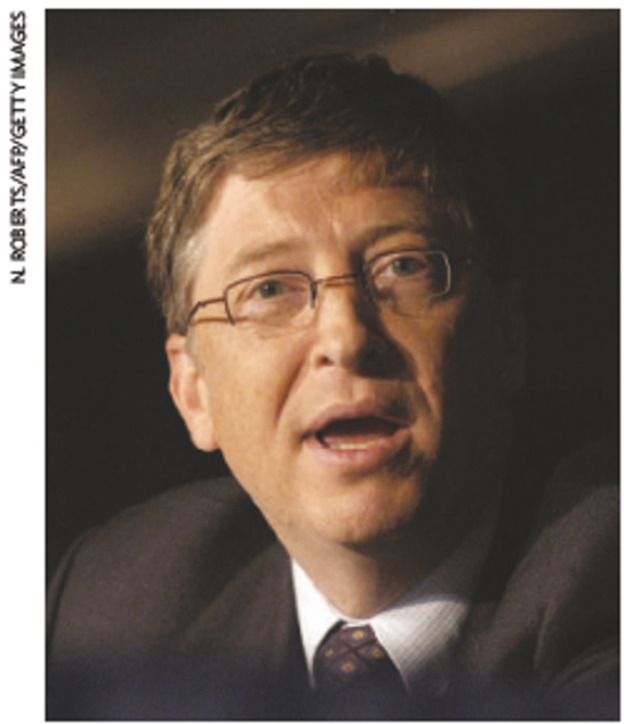

Not everyone agrees with Bill Gates' idea of a miss ion-oriented approach to vaccine discovery.

next week's XVI International Aids Conference in Toronto, Canada. There are concerns about both the selection process (see'A controversial choice?') and the wisdom of investing so much money in a big-science approach.

"We are having to learn a new culture and language relating to these milestones and directed research," says Robin Weiss of University College London, UK, who has won a \$25.3-million grant. His consortium involves 11 labs in at least 6 countries. Getting them to work together effectively will be an organizational challenge, Weiss says, although he adds that they already "feel like a family". But Weiss is one of several AIDS researchers who argue that the community already cooperates well. "I was a little surprised at the implication that we needed the Gates Foundation to tell us to collaborate, he says.

Many researchers are concerned about the level of funding going to a mission-oriented approach versus investigator-driven science. "It's a difficult balance to get in vaccine discovery - it's not development, but research," says Weiss. "I don't thinkan AIDS vaccine has been held up because we didn't know how to collaborate. The limiting factor is a scientific breakthrough, a bright idea and new thinking."

Others argue that large mission-oriented grants could hold back the science. "You are going to get bad decisions," predicts one AIDS researcher who requested anonymity. He argues that the approach hands scientific choices to bureaucrats, and that the concentration of so much money in so few hands is a recipe for turf wars and nepotism - a criticism vocally expressed by US researchers left out of the CHAVI funding framework. He also questions whether large collaborations - which make sense in astronomy, where teams often study the same object at different wavelengths, or in tackling the vast amounts of data coming from the Human Genome Project — are as applicable to the experiments of vaccine research.

The task of making big science work for HIV falls to Adel Mahmoud, who will retire next month as president of Merck's Vaccine Division to become chief executive of the Global HIV Vaccine Enterprise.

Kazatchkine for one is a convert, arguing that the "incredible egotism" of individuals and institutions often creates communities that lack the vision to organize themselves productively: "If Mahmoud succeeds, he will demonstrate a new way of doing science, where collaboration becomes as important as competition, giving research a new image."

Declan Butler

See also pages 602 and 617.
ON THE RECORD

\section{“Americans aren't gullible enough to believe that they came from a fish."}

Creationist John Morris on a new Museum of Creationism in Kentucky.

\section{CToday, with all the pollution, you cannot get cleaner water than melted ice-cap water."}

Salik Haard promotes his new beer. made with water from Greenland's shrinking glaciers.

\section{NUMBER CRUNCH}

Scientists this week announced the longest-ever electronic tracking of a migrating animal, a diminutive seabird called the sooty shearwater.

\section{$65,000 \mathrm{~km}$ is} the distance travelled by a sooty shearwater in 200 days.

$5,000 \mathrm{~km}$ is the distance travelled each year by some caribou, the land animals that migrate the farthest.

$800 \mathrm{~g}$ is the average weight of an adult sooty shearwater.

$189 \mathrm{~kg}$ is the average weight of a caribou.

\section{SCORECARD}

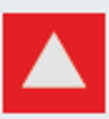

Chemical analysis Isotope ratiomass spectroscopy showed that testosterone found

in the urine of Floyd Landis, winner of the Tour de France, did not have the same carbon isotope ratio as other hormones in the sample, showing it had a different, external source.

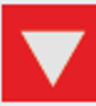

Cimate porn A report by the Institute for Public Policy Research, a UK think-tank, highlights the "quasireligious register of doom, death, judgement, heaven and hell" in alarmistclimate reporting that can become "secretly thrilling". This is not, the institute argues, a helpful way of framing things. 